Groenewegen, P.P., Berg, A.E. van den, Maas, J., Verheij, R.A., Vries, S. de. Is a green residential environment better for health? If so, why? Annals of the Association of American Geographers: 2012, 102(5), 996-1003

\begin{tabular}{|l|l|}
$\begin{array}{l}\text { Postprint } \\
\text { Version }\end{array}$ & 1.0 \\
\hline Journal website & http://www.tandfonline.com/doi/abs/10.1080/00045608.2012.674899 \\
\hline Pubmed link & $\underline{\text { http://www.ncbi.nlm.nih.gov/pubmed/23145512 }}$ \\
\hline DOI & $10.1080 / 00045608.2012 .674899$ \\
\hline
\end{tabular}

This is a NIVEL certified Post Print, more info at http://www.nivel.eu

\title{
Is a Green Residential Environment Better for Health? If So, Why?
}

\author{
Peter P. Groenewegen, * Agnes E. VAn Den Berg, $†$ Jolanda MaAs, $\ddagger$ Robert A. \\ VERHEIJ,§ AND SJERP DE VRIES\#
}

*NIVEL-Netherlands Institute for Health Services Research, and Department of Human Geography and Department of Sociology, Utrecht University, Utrecht, The Netherlands †Alterra Wageningen UR, Wageningen, The Netherlands ‡EMGO+ Institute, Department of Public and Occupational Health, VU University Medical Center, Amsterdam, The Netherlands

SNIVEL-Netherlands Institute for Health Services Research, Utrecht, The Netherlands \#Wageningen UR Landscape Centre, Wageningen, The Netherlands

Over the past years our group has been working on a coherent research program on the relationships between greenspace and health. The main aims of this "Vitamin G" program (where G stands for green) were to empirically verify relationships between greenspace in residential areas and health and to gain insight into mechanisms explaining these relationships. In this article, we bring together key results of our program regarding the relevance of three possible mechanisms: stress reduction, physical activity, and social cohesion. The program consisted of three projects in which relationships between greenspace and health were studied at national, urban, and local scales. We used a mixedmethod approach, including secondary analysis, survey data, observations, and an experiment. The results confirmed that quantity as well as quality of greenspace in residential areas were positively related to health. These relationships could be (partly) explained by the fact that residents of greener areas experienced less stress and more social cohesion. In general, residents of greener areas did not engage in more physical activity. The article concludes with a discussion of the practical implications of these findings and identification of areas that need more in-depth research.

The idea that greenspace in the residential environment can promote health has a long history in environmental planning (Hartig et al. 2011).

A notable example is Howard's ([1902] 1946) Garden Cities of Tomorrow. The author pleaded that the advantages of town and countryside should be integrated in garden cities with optimal opportunities for health and well-being. In practice, 
however, it has been difficult to realize this vision. Due to large-scale demands for housing and other services, urban greenspace has increasingly come under threat. What are the consequences of these developments for public health? Does a green residential environment indeed promote health? If so, why? The relationship between greenspace and health has only recently become a theme for empirical research (Hartig et al. 2011; De Vries et al. 2011). Prior to theVitamin G project, only two epidemiological studies had investigated the direct relationship between greenspace and health (Takano, Nakamura, and Watanabe 2002; De Vries et al. 2003). These studies suggested a positive link between the amount of greenspace in the residential environment and health but also raised questions about the strength and robustness of this relation and the mechanisms behind it.

\section{Possible Mechanisms BeHIND THE GREensPaCE-HEALTh RELATIONSHIP}

Three mechanisms - stress reduction, physical activity, and social cohesion-are frequently mentioned in the literature. They are well-known predictors of health (U.S. Department of Health and Human Services 1996) and might also be related to the availability of greenspace.

\section{Stress Reduction}

Many people consider contact with nature one of the most powerful ways to obtain relief from stress and mental fatigue (Grahn and Stigsdotter 2003). This mechanism can be regarded as a remnant of evolution in natural environments, during which humans have developed a partly genetic readiness to respond positively to unthreatening natural settings that were favorable to well-being and survival (Ulrich 1993).

Natural scenes seem to have a unique attention-drawing quality (soft fascination; Berto, Massaccesi, and Pasini 2008), which repletes directed attention and replaces negative emotions (S. Kaplan 1995). Evidence for these restorative responses has been collected through field studies in such diverse settings as wilderness areas (Hartig, Mang, and Evans 1991) and gardens (Ottosson and Grahn 2005). Even viewing nature from the window of one's home can provide "micro-restorative" opportunities that can build resilience against stress (R. Kaplan 2001). Viewing slides or videos of natural environments leads to a faster and more complete stress recovery than viewing built environments (Ulrich et al. 1991; Van den Berg, Koole, and Van der Wulp 2003).

In sum, there is substantial evidence that restoration from stress andmental fatigue is a potentially important mechanism in the relationship between greenspace and health.

\section{Physical Exercise}

Peoplemore easily undertake physical activities, such as cycling and walking, in aesthetically appealing environments (Pikora et al. 2003; Owen et al. 2004), perhaps even for longer periods of time (Pretty et al. 2007). The evidence for a positive influence of greenspace on physical activities, however, is as yet mixed and inconclusive (positive: Ellaway, Macintyre, and Bonnefoy 2005; McGinn et al. 2007; no relation: Hoehner et al. 2005; Hillsdon et al. 2006; McGinn et al. 2007; negative: Duncan and Mummery 2005).

Apart from differences in the geographic context of studies, this mixed evidence might be related to the intrinsic character of the motivation to exercise. People who 
want to be active will find themselves a way to do so, even if it requires taking the car to travel to a faraway green area. Moreover, some greenspaces invite passive forms of recreation rather than active forms.

Thus, although intuitively plausible, the literature suggests that physical activity is not a strong candidate for explaining the relationship between greenspace and health.

\section{Social Cohesion}

Meeting opportunities are important for social ties with neighbors, leading to more cohesive communities (Volker, Flap, and Lindenberg 2007). The presence of green in common spaces might attract residents to outdoor spaces, leading to more frequent contacts (Coley, Kuo, and Sullivan 1997). Studies in an underprivileged area of Chicago provide indications for a positive relation between green public facilities and social ties (Kuo, Sullivan, and Wiley 1998; Kweon, Sullivan, and Wiley 1998). Besides offering meeting opportunities, greenspace can promote a general sense of community, which might decrease feelings of loneliness and increase social support (Prezza et al. 2001). Overall, there are several indications for social cohesion as a possible mechanism underlying the relation between greenspace and health. Against this background, the Vitamin G program aimed to empirically verify a positive relationship between greenspace in the residential environment and health and to evaluate the importance of the three mechanisms mentioned. In the remainder of this article, we first briefly describe the study method, followed by an overview of the main findings. In this overview, we bring together the findings regarding the relevance of the three explanatory mechanisms (stress reduction, physical activity, and social cohesion).

\section{STUDY DESIGN, DATA, AND METHODS}

The Vitamin G research program consisted of three projects, each with a different scope (Groenewegen et al. 2006). The first project had a national scope and used data from TheNetherlands as a whole. The second project focused on eighty neighborhoods in four Dutch cities (urban scale). The third project studied allotment gardens in and around twelveDutch cities (local scale).

In each project, greenspace indicators were linked to health indicators. All analyses were carried out at the level of individuals, and multilevel analysis was used to control for the nesting of individuals in neighborhoods wherever necessary. The analyses were controlled for characteristics known to be associated with health (e.g., age, gender, education, income, urbanity). Given the egalitarian health care system and the high density of health service provision in The Netherlands, there was no need to add additional variables regarding access to health care. In the national study, greenspace around people's homes was related to subjective and objective health. Land use data were derived from the National Land CoverClassification database and aggregated to the percentage of greenspace in circles with a 1- and 3-km radius around the six-digit postal code of the respondents' addresses. Health data were derived from the second Dutch National Survey of General Practice (Westert et al. 2005). This was a two-stage sample of 104 family practices, a one-page mailed questionnaire among the practice population of approximately 400,000 people (in TheNetherlands, virtually thewhole population is registered with a practice), 300,000 respondents (76\%), and health interviews among a random sample of the practice population, resulting in 12,700 respondents (64\%). Objective health data were derived from electronic medical records of the practice populations. 
The urban neighborhood study related quantity and quality of greenspace to selfreported health. Data on health and explanatory variables (related to stress, physical activity, and social cohesion) were collected throughmailed questionnaires (1,641 respondents) sent to residents of twenty neighborhoods (average size 2,200 inhabitants) in four cities. To measure the quantity of larger green areas (parks, etc.), we used land use data from Statistics Netherlands. Trained observers assessed the quality of three larger green areas as well as the amount and quality of streetscape greenery (not captured in the land use data) at four preselected points within each neighborhood. Quality indicators encompassed accessibility, maintenance, variation, naturalness, colorfulness, clear arrangement, shelter, absence of litter, safety, and general impression.

The allotment garden study involved a comparison of gardeners and their neighborswith no allotment. The study consisted of a survey among members of twelve allotment sites (121 respondents) and a control group of their neighbors without an allotment (63 respondents).

The survey included self-reported health and measures of stress, physical activity, and social cohesion.

A distinction was made between respondents younger or older than sixty-two. In addition to the survey, a field experiment among thirty allotment gardeners was conducted. The gardeners first performed a stressful task and were then randomly assigned to thirty minutes of gardening or indoor reading. Salivary cortisol levels and self-reportedmood were repeatedly measured before and after the stressful task and during and after the restorative activity.

\section{RESULTS}

\section{Greenspace and Health}

The national study showed that residents of greener areas felt healthier than residents of less green areas (Maas et al. 2006; see Figure 1). Furthermore, for fifteen out of twenty-four physician-assessed morbidity clusters, the incidence rates were negatively related to the amount of greenspace within a 1-km radius around people's homes (Maas, Verheij, et al. 2009). The relationship was strongest for anxiety disorders and depression; for depression the chances were 1.33 times higher in areas with little greenspace than in areas with very much greenspace. Across different studies, relationships between greenspace and health tended to be stronger for individuals of a lower socioeconomic status (SES), younger age groups, and the elderly.

In the urban neighborhood study, both the quantity and quality of nearby green areas and streetscape greenery were positively related to self-rated health, number of acute complaints, and mental health status (Van Dillen et al. 2011).

In the allotment garden study, gardeners sixty-two years and older scored significantly better than their neighbors on physical disabilities, health complaints, and family physician consultations and marginally better on perceived general health and chronic illness than their neighbors in the same age category (Van den Berg, VanWinsum-Westra, et al. 2010). 


\section{[FIGURE 1]}

\section{Stress Reduction}

The national study investigated the extent to which greenspace can buffer adverse health impacts of stressful life events (Van den Berg, Maas, et al. 2010).

Detrimental impacts of stressful life events on perceived general and acute health complaints were less strong for respondents with much greenspace in a 3-km radius around their home than for respondents with little greenspace in a 3-km radius (Figure 2). The same pattern was observed for perceivedmental health, although it was marginally significant.

In the urban neighborhood study, stress turned out to be a full mediator of the relationship between the quantity of streetscape greenery and mental health and a partial mediator of the relationships with self-rated health and number of acute health complaints. Stress explained one fifth to over two fifths of the relationships of quantity of streetscape greenery with these health indicators (Figure 3). In the relationships of health indicators with quality of streetscape greenery, stress was always a partial mediator (De Vries et al. forthcoming).

In the allotment gardening survey, 86 percent of the gardeners reported feeling less stressed after a visit to their allotment garden; 56 percent rated stress relief as a very important reason for gardening (Van den Berg, VanWinsum-Westra, et al. 2010).Older allotment gardeners had experienced less stress recently and seemed better able to cope with stress. The field experiment showed that gardening led to stronger decreases in the stress hormone cortisol than reading (Van den Berg and Custers 2011).

\section{Physical Activity}

\section{[FIGURE 2]}

At the national scale no relationships were found between the amount of greenspace in the area and time spent on physical activity in general, sports, andwalking for commuting purposes (Maas et al. 2008). For walking and cycling in leisure time, residents of areas with much greenspace spent even less time on these activities than residents of areas with little greenspace. Greenspace and cycling for commuting purposes were positively related, but this could not explain the relationship between greenspace and health.

The urban neighborhood study also indicated that total physical activity could not explain the relationship between greenspace and health, as it was not related to greenspace (De Vries et al. forthcoming). Only "green” physical activities (activities that could be undertaken in the public space of the neighborhood, such as walking and cycling) were related to greenspace but to a lesser extent than stress. In all analyses, green physical activity was at best a partial mediator of the relationships between quantity and quality of streetscape greenery and the self-reported health indicators. Green physical activity explained less than 10 percent of the direct relationships of quantity of streetscape greenery with the health indicators (Figure 3). [figure3] In the allotment gardening study, 50 percent of gardeners found staying active very important for having an allotment garden (Van den Berg, Van WinsumWestra, et al. 2010). Younger and older allotment gardeners had better scores on physical activity than the control group. 
In summer, 84 percent of the allotment gardeners met the Dutch public health recommendations for physical activity compared to only 62 percent of the control group.

\section{Social Cohesion}

The national study showed that residents with a high amount of greenspace in their residential environment felt less lonely and less often experienced a shortage of social support than residents with a low amount of greenspace in their residential environment (Maas, Van Dillen, et al. 2009). The amount of greenspace was not related to the actual frequency of contact with neighbors or the number of supportive interactions. All relationships between greenspace and self-reported health, number of health complaints, andmental health were at least partially mediated by loneliness and shortage of social support. The relationship between greenspace and mental health could even be fully explained by the fact that residents of greener areas less often experienced a shortage of social support.

In the urban neighborhood study, the finding that residents of neigborhoods with higher amounts of streetscape greenery reported less acute health complaints and better mental health could be fully explained by the stronger social cohesion in greener neighborhoods.

Social cohesion also partly explained the positive relationship between quantity of streetscape scenery and self-rated general health. Overall, social cohesion explained one fifth to one third of the relationships between quantity of streetscape greenery and the health indicators (see Figure 3). Furthermore, social cohesion was always a partial mediator in the analyses of the relationships of health indicators with the quality of streetscape greenery (De Vries et al. forthcoming).

Only 17 percent of allotment gardeners mentioned social contacts as a very important motive for gardening (Van den Berg, VanWinsum-Westra, et al. 2010).Nevertheless, older gardeners felt significantly less lonely than neighbors in the same age group, and they also reported having marginally more social contacts with friends.

\section{Discussion}

This article has provided a summary of the results of the Vitamin $G$ research program, with an emphasis on the mechanisms behind the relationship between greenspace and health. The studies within the program provide converging evidence for a positive relationship between greenspace in the residential environment and health, using different self-reported and objective greenspace and health indicators. Stress reduction and social cohesion were found to be the most important mechanisms.

The relationships between greenspace and health are consistent with other epidemiological studies conducted in England (Mitchell and Popham 2007), Denmark (Nielsen and Hansen 2007), and Sweden (Bj”ork et al. 2008). However, a recent study in New Zealand found no relationship between greenspace and mortality (Richardson et al. 2010). The authors explained this in terms of diminishing marginal returns at the large amount of greenspace, characteristic for New Zealand residential neighborhoods.

Greenspace was found to be especially important for mental health. In the national study that used physician-assessed morbidity, the strongest relationships were found for anxiety disorders and depression. 
This is in line with findings from previous studies that have also consistently reported stronger positive impacts of contact with greenspace on mental than on physical health (e.g., Sugiyama et al. 2008).

Also consistent with previous research (e.g.,Mitchell and Popham 2008), the overall results suggest that people with lower SES, younger people, and the elderly benefit more from green areas in their residential environment.

Although exposure to greenspace was not measured, these findingsmight be tentatively explained by the fact that these groups spend more time in the vicinity of their homes and thus are more exposed to characteristics of their residential environment. Moreover, those who spend less time in the residential environment might be additionally affected by a lack of greenspace as is typical for many work environments (Kwan 2009).

The mediation analyses in the neighborhood study suggest that stress reduction and social cohesion, in that order, are the most important mechanisms in explaining the relationship between greenspace and health. These findings are consistent with findings of previous research that have consistently shown strong links between greenspace and stress and social cohesion and only weak and mixed evidence for links between greenspace and physical activity. Few studies, however, have directly tested mediational models. As a notable exception, a survey in Australia showed that recreational walking could fully explain the link between greenness and physical health, whereas the relationship between greenness and mental health was partly accounted for by recreational walking and social cohesion (Sugiyama et al. 2008). These results are consistent with the finding in the Vitamin $G$ program that social cohesion is an important mediator of greenspace-health relationships. The findings of the Vitamin G program with respect to the mediational role of physical activities (e.g., recreational walking) were more mixed and inconclusive, however.

\section{STRENGTHS AND LIMITATIONS}

Contrary to many other studies, the Vitamin G program encompassed different geographical scales and levels of urbanity, taking into account different subjective as well as objective health indicators and various indicators of greenspace. Most of the VitaminGstudies also used large data sets and state-of-the-art statistical (multilevel and mediational) analyses. Same-source bias was avoided by using objective indicators for greenspace along with observations. These aspects contribute to the validity and practical applicability of the results.

The most important limitations relate to exposure and causality, probably the two most difficult issues to address in studies of environment and health. The length and intensity of residents' exposure to green elements was not directly measured. With regard to causality, selection cannot be ruled out as an alternative explanation for our results but can only be made less plausible by using adequate control variables in the analyses.

Other limitations include the fact that we investigated only three mechanisms, although there are several other possible candidates (e.g., connectedness to nature, increased vitality; cf. Hartig et al. 2011). Furthermore, we have only looked at relatively nearby greenspace. For some purposes, people might seek out more distant areas. Moreover, our studies were done in a densely populated country with very little (wild) nature. As a consequence, the importance of nearby greenspace for 
health might have been overestimated as compared to other countries with more abundant nature (Richardson et al. 2010).

\section{Future Research and Practical Implications}

Future research should address these limitations.

Better measurements of exposure are possible through Global Positioning System

(GPS) measurements, as already used in transport geography. Using such measurements could provide detailed information on the time people spend in particular environments during daily activities (Kwan 2009). Direct selection effects can be ruled out with longitudinal studies, which include geocoded information. With respect to implications for spatial planning and public health, it is important to study in more detail which aspects of greenspace are related to which mechanisms and which health outcomes. An important general guideline that can be derived from the Vitamin G program is that the quality of urban greenspace, besides quantity, has an additional beneficial effect on health.

Proximity (comparing distances of 1 and $3 \mathrm{~km}$ ) did not make much difference for self-rated health, but nearby green areas seem to be more important for physicianassessed morbidity, whereas less proximate areas seem to be more important for buffering stress. Moreover, we still do not know much about the relative contribution of greenspace compared to other environmental characteristics, both socioeconomic and physical.

More insight is also needed in possible international variation in the greenspacehealth relationship.

Research in northwestern Europe indicates that the relationship exists, irrespective of large differences in population density and types of greenspace, but as greenspace might affect different individuals in different ways, more attention to the interaction between individuals and their environment is required.

By answering these questions, future research could provide a fuller understanding of the intricacies of the greenspace-health relationship and help to design effective and health-promoting greenspace policies.

\section{REFERENCES}

Berto, R., S. Massaccesi, and M. Pasini. 2008. Do eye movements measured across high and low fascination photographs differ? Addressing Kaplan's fascination hypothesis. Journal of Environmental Psychology 28: 185-91.

Bjork, J., M. Albin, P. Grahn, H. Jacobsson, J. Ardo, J. Wadbro, P.-O. O stergren, and E. Ska"rba"ck. 2008. Recre- ational values of the natural environment in relation to neighbourhood satisfaction, physical activity, obesity and wellbeing. Journal of Epidemiology and Community Health 62 (e2): 1-7.

Coley, R. L., F. E. Kuo, and W. C. Sullivan. 1997. Where does community grow? The social context created by nature in urban public housing. Environment and Behaviour 29:468-94.

De Vries, S., T. Classen, S.-M. Eigenheer-Hug, K. Korpela, J. Maas, R. Mitchell, and P. Schantz. 2011. Contributions of natural environments to physical activity; Theory and evidence base. In Forests, trees and human health, ed. K.

Nilsson, M. Sangster, C. Gallis, S. De Vries, K. Seeland, and J. Schipperijn, 205-44. New York: Springer.

De Vries, S., S. M. E. Van Dillen, P. P. Groenewegen, and P. Spreeuwenberg. Forthcoming. Streetscape greenery and human health: Stress, social cohesion and physical activity as possible mediators. 
Groenewegen, P.P., Berg, A.E. van den, Maas, J., Verheij, R.A., Vries, S. de. Is a green residential environment better for health? If so, why? Annals of the Association of American Geographers: 2012, 102(5), 996-1003

De Vries, S., R. A. Verheij, P. P. Groenewegen, and P. Spreeuwenberg. 2003. Natural environments-Healthy environments? An exploratory analysis of the relation- ship between greenspace and health. Environment and Planning A 35:1717-31.

Duncan, M., and K. Mummery. 2005. Psychosocial and environmental factors associated with physical activity among city dwellers in regional Queensland. Preventive Medicine 40:363-72.

Ellaway, A., S. Macintyre, and X. Bonnefoy. 2005. Graffiti, greenery, and obesity in adults: Secondary analysis of European cross sectional survey. British Medical Journal 31:61112.

Grahn, P., and U. A. Stigsdotter. 2003. Landscape planning and stress. Urban Forestry and Urban Greening 2:1-18.

Groenewegen, P. P., A. E. Van den Berg, S. De Vries, and R. A. Verheij. 2006. Vitamin G: Effects of green space on health, well-being, and social safety. BMC Public Health 6:149.

Hartig, T., M. Mang, and G. W. Evans. 1991. Restorative effects of natural environment experiences. Environment and Behavior 23:3-27.

Hartig, T., A. E. Van den Berg, C. M. Hagerhall, M. Tomalak, N. Bauer, R. Hansmann, A. Ojala, et al. 2011. Health benefits of nature experiences: Psychological, social and cultural processes. In Forests, trees and human health, ed.

K. Nilsson, M. Sangster, C. Gallis, S. De Vries, K. See- land, and J. Schipperijn, 127-68. New York: Springer.

Hillsdon, M., J. Panter, C. Foster, and A. Jones. 2006. The relationship between access and quality of urban green space with population physical activity. Journal of the Royal Institute of Public Health 120:1127-32.

Hoehner, C. M., L. K. Brennan Ramirez, M. B. Elliott, S. L. Handy, and R. C. Brownson. 2005. Perceived and objective environmental measures and physical activity among urban adults. American Journal of Preventive Medicine 28:105-16.

Howard, E. [1902] 1946. Garden cities of tomorrow. London: Faber and Faber. Kaplan, R. 2001. The nature of the view from home-Psychological benefits. Environment and Behavior 33:507-42.

Kaplan, S. 1995. The restorative benefits of nature: Toward an integrative framework. Journal of Environmental Psychology 15:169-82.

Kuo, F. E., W. C. Sullivan, and A. Wiley. 1998. Fertile ground for community: Inner-city neighborhood com- mon spaces. American Journal of Community Psychology 26:823-51.

Kwan, M.-P. 2009. From place-based to people-based expo- sure measures. Social Science and Medicine 69:1311-13.

Kweon, B. S., W. C. Sullivan, and A. Wiley. 1998. Green common spaces and the social integration of inner-city older adults. Environment and Behavior 30: 823-58.

Maas, J., S. M. E. Van Dillen, R. A. Verheij, and P. P. Groenewegen. 2009. Social contacts as a possible mechanism behind the relation between green space and health: A multilevel analysis. Health \& Place 15:586-92.

Maas, J., R. A. Verheij, S. De Vries, P. Spreeuwenberg, F. Schellevis, and P. P. Groenewegen. 2009. Morbidity is related to a green living environment. Journal of Epidemiology and Community Health 63:967-73.

Maas, J., R. A. Verheij, P. P. Groenewegen, S. De Vries, and P. Spreeuwenberg. 2006. Green space, urbanity and health: How strong is the relation? Journal of Epidemiology and Community Health 60:587-92.

Maas, J., R. A. Verheij, P. Spreeuwenberg, and P. P. Groenewegen. 2008. Physical activity as a possiblemechanism behind the relationship between green space and health: $A$ multilevel analysis. BMC Public Health 8:206.

McGinn, A. P., K. R. Evenson, A. H. Herring, and S. L. Huston. 2007. The relationship between leisure, walking and transportation activity with the natural environment. Health \& Place 13:588-602.

Mitchell, R., and F. Popham. 2007. Greenspace, urbanity and health: Relationships in England. Journal of Epidemiology and Community Health 61:681-83.

2008. Effect of exposure to natural environment on health inequalities: An observational population study. The Lancet 372 (9650): 1655-60.

Nielsen, T. S., and K. B. Hansen. 2007. Do green areas affect health? Results from a Danish survey on the use of green areas and health indicators. Health and Place 13:839-50. 
Groenewegen, P.P., Berg, A.E. van den, Maas, J., Verheij, R.A., Vries, S. de. Is a green residential environment better for health? If so, why? Annals of the Association of American Geographers: 2012, 102(5), 996-1003

Ottosson, J., and P. Grahn. 2005. A comparison of leisure time spent in a garden with leisure time spent indoors: On measures of restoration in residents in geriatric care. Landscape Research 30:23-55.

Owen, N., N. Humpel, E. Leslie, A. Bauman, and J. Sallis. 2004. Understanding environmental influences on walking: Review and research agenda. American Journal of Preventive Medicine 27:67-76.

Pikora, T., B. Giles-Corti, F. Bull, K. Jamrozik, and R. Donovan. 2003. Developing a framework for assessment of the environmental determinants of walking and cycling. Social Science and Medicine 56:1693-1703.

Pretty, J., J. Peacock, R. Hine, M. Sellens, N. South, and M. Griffin. 2007. Green exercise in the UK countryside: Effects on health and psychological well-being, and implications for policy and planning. Journal of Environmental Planning and Management 50:211-31.

Prezza, M., M. Amici, T. Roberti, and G. Tedeschi. 2001.

Sense of community referred to the whole town: Its relations with neighboring, loneliness, life satisfaction, and area of residence. Journal of Community Psychology 29:29-52.

Richardson, E., J. Pearce, R. Mitchell, P. Day, and S. Kingham. 2010. The association between green space and cause-specific mortality in urban New Zealand: An ecological analysis of green space utility. BMC Public Health 10:240.

Sugiyama, T., E. Leslie, B. Giles-Corti, and N. Owen. 2008.

Associations of neighbourhood greenness with physical and mental health: Do walking, social coherence and local social interaction explain the relationships? Journal of Epidemiology and Community Health 62:e9.

Takano, T., K. Nakamura, and M. Watanabe. 2002. Urban residential environments and senior citizens' longevity in megacity areas: The importance of walkable green spaces. Journal of Epidemiology and Community Health 56:913-18.

Ulrich, R. S. 1993. Biophilia, biophobia and natural landscapes. In The biophilia hypothesis, ed. S. R. Kellert and E. O. Wilson, 73-137. Washington, DC: Island.

Ulrich, R. S., R. F. Simons, B. D. Losito, E. Fiorito, M. A. Miles, and M. Zelson. 1991. Stress recovery during exposure to natural and urban environments. Journal of Environmental Psychology 11:201-03.

U.S. Department of Health and Human Services. 1996. Physical activity and health: A report of the Surgeon General.

Atlanta, GA: U.S. Department of Health and Human Services, Centers for Disease Control and Prevention, National Center for Chronic Disease Prevention and Health Promotion.

Van den Berg, A. E., and M. H. G. Custers. 2011. Gardening promotes neuroendocrine and affective restoration from stress. Journal of Health Psychology 16:3-11.

Van den Berg, A. E., S. L. Koole, and N. Y. Van der Wulp. 2003. Environmental preference and restoration: How are they related? Journal of Environmental Psychology 23:2135-46.

Van den Berg, A. E., J. Maas, R. A. Verheij, and P. P. Groenewegen. 2010. Green space as a buffer between stressful life events and health. Social Science and Medicine 70:1203-10.

Van den Berg, A. E., M. Van Winsum-Westra, S. De Vries, and S. Van Dillen. 2010. Allotment gardening and health: A comparative survey among allotment gardeners and their neighbors without an allotment. Environmental Health 9:74.

Van Dillen, S. M. E., S. De Vries, P. P. Groenewegen, and P. Spreeuwenberg. 2011. Greenspace in urban neighbourhoods and residents' health: Adding quality to quantity. Journal of Epidemiology and Community Health (epub ahead of print).

Volker, B., H. D. Flap, and S. Lindenberg. 2007. When are neighbourhoods communities? Community in Dutch neighbourhoods. European Sociological Review 23:99-114.

Westert, G. P., F. G. Schellevis, D. H. De Bakker, P. P. Groenewegen, J. M. Bensing, and J. Van der Zee. 2005. Monitoring health inequalities through general practice: The second Dutch national survey of general practice. European Journal of Public Health 15: 59-65. 


\section{FIGURES}

Figure 1. Estimated relationship between amount of greenspace (in a 3-km radius) and self-perceived health (percentage stating that their health is less than good) based on a logistic multilevel model controlling for age, gender, income, education, and urbanity (taken from Maas et al. 2006). (Color figure available online.)

\section{Relation between green space and health}

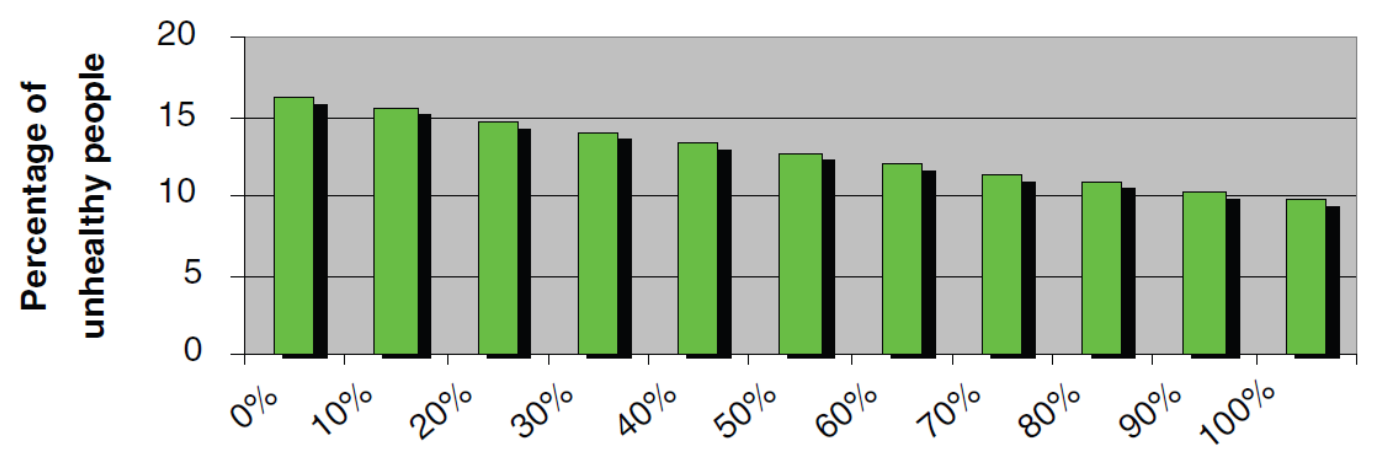

Amount of green space

Figure 2. Estimated marginal means of perceived general health $(1=$ excellent; $5=$ poor) as a function of stressful life events in past three months (white bars: no life events; black bars: life event(s)) and amount of greenspace in a 1-km and 3-km radius, controlling for age, gender, income, education, and of urbanity (taken from Van den Berg, Maas et al. 2010).

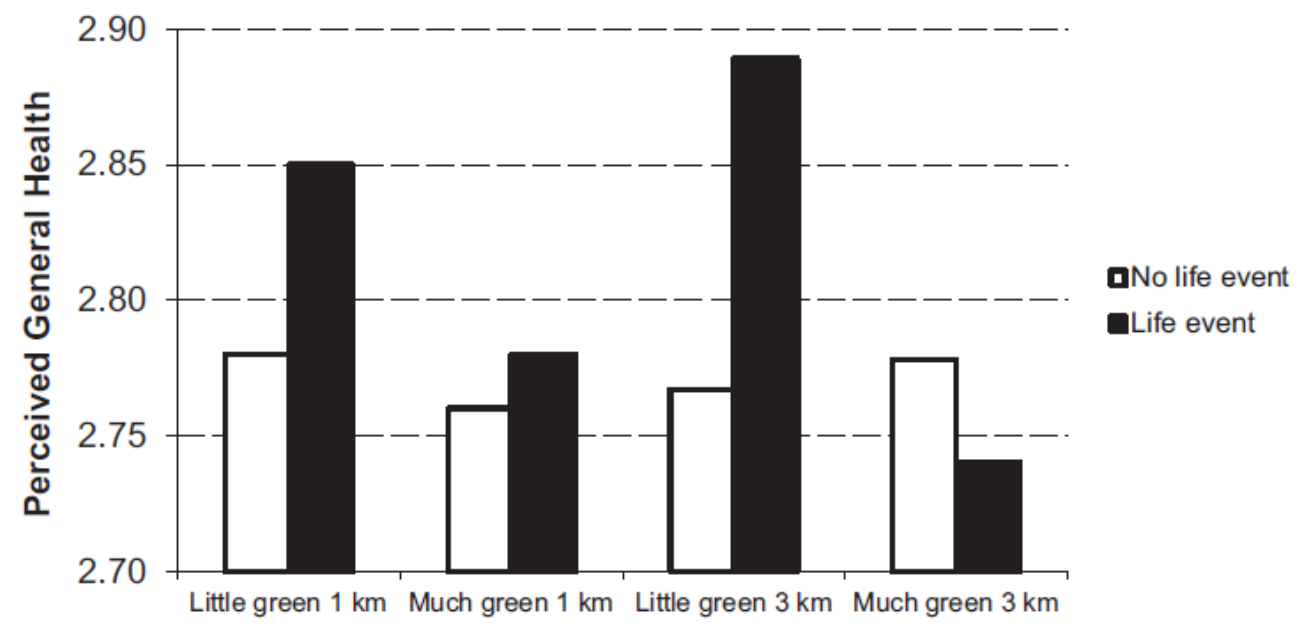


Figure 3. Indirect effect on health indicators as percentage of total effect of quantity of streetscape greenery for the three mediators separately and combined, controlling for gender, age, education, income, life events, having children living at home, smoking, and excessive drinking (taken from De Vries et al. forthcoming). PA = physical activity. (Color figure available online.)

\section{Mediated part of effect for quantity (\%)}

Stress $\square$ Cohesion $\square$ Green PA $\square$ All three

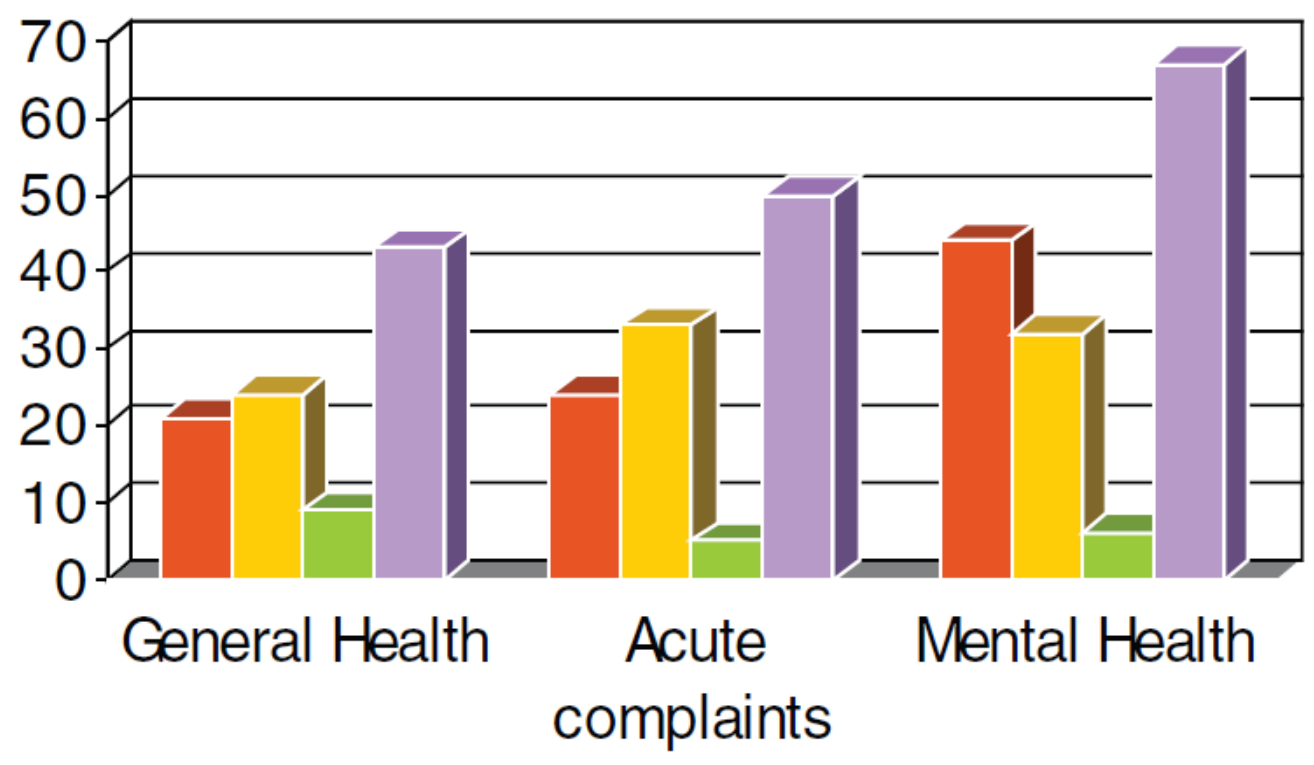

